\title{
Currents, predators, and the aggregation of the gastropod Buccinum undatum around bait
}

\author{
Véronique Lapointe $^{1, *}$, Bernard Sainte-Marie $\mathrm{e}^{2, * *}$ \\ ${ }^{1}$ Département d'océanographie, Université du Québec à Rimouski, Rimouski, Québec, Canada G5L 3A1 \\ ${ }^{2}$ Ministère des Pèches et des Océans, Institut Maurice-Lamontagne, 850 route de la Mer, C.P. 1000, Mont-Joli, Québec,
} Canada G5H 324

\begin{abstract}
Aggregation of the gastropod Buccinum undatum Linnaeus around bait was studied at 2 subtidal sites, with different current regimes, in the northern Gulf of Saint Lawrence, Canada. Timelapse photography, SCUBA and current recordings were used to measure and interpret movement and behavior of whelks up to $25 \mathrm{~m}$ away from the bait. Objectives were to test the hypothesis of upstream movement to bait, and to determine relations between whelk arrival rate at the bait and currents and predators. In the absence of bait, $75.8 \%$ of whelks were static or buried. In the presence of bait, whelks in a 20 to $60^{\circ}$ downstream sector to a maximum distance of $20 \mathrm{~m}$ moved towards the bait. Whelks apparently oriented to the bait by chemotaxis. Average crawling speed towards the bait varied from 7.3 to $15.1 \mathrm{~cm} \mathrm{~min}^{-1}$ and was independent of current speed. More whelks arrived at bait per unit time when current direction changed gradually than when current was directionally stable; this was due to exploitation of new grounds and to depletion of the downstream population respectively. A model and indirect field evidence indicate that whelk arrival rate is depressed by sudden and marked changes in current direction, because whelks are unable to track the shi,ting odor plume. Arrival rate was positively correlated with current speed with time lags of up to $3 \mathrm{~h}$, but tended 10 be negatively correlated with longer time lags. Arrival rate was negatively correlated with the numbe $e_{1}$ of predators (Cancer irroratus and Hyas araneus) at bait with time lags of up to $1 \mathrm{~h}$, but positively correlated with numbers of $H$. araneus at bait with longer time lags. These correlations are explained by changes in the characteristics of the odor plume and by agonistic interactions.
\end{abstract}

\section{INTRODUCTION}

Scavengers are conspicuous members of polar and deep-sea benthos, where they may play a major role in community structure and energy transfer (Arnaud 1970, Dayton \& Hessler 1972, Stockton \& DeLaca 1982, Smith 1986). Factors governing detection and localization of carrion, and the spatial and temporal scales for aggregation and subsequent dispersal of scavengers, are thus important for several benthic community processes and rates (Ingram \& Hessler 1983, Smith 1985. Priede et al. 1991). This information is also directly relevant to the management of fisheries that depend on baited traps and hooks (McQuinn et al. 1988, Løkkeborg et al. 1989, Miller 1990).

It has been hypothesized that some scavengers

\footnotetext{
- Present address: 747 Place Monette, Sainte-Thérèse, Québec, Canada J7E $3 Z 3$

- Addressee for correspondence
}

detect sound or pressure waves generated by a falling nekton carcass as it hits the bottom (Dahl 1979, Smith \& Baldwin 1982), or home to the vicinity of bait by mechanoreception of the sounds produced by aggregated feeders (Smith \& Baldwin 1984), Attraction of scavengers might also occur through the successive collapse of territories held by individuals closer to bait (Isaacs \& Schwartzlose 1975, Smith 1985). However, many observations of scavengers arriving at bait from downstream directions (e.g. McLeese 1973, Miller 1980, Busdosh et al. 1982, Wilson \& Smith 1984, Himmelman 1988) indicate that stimuli are propagated to some extent by advection, as is the case for chemical attractants (Okubo 1980, Atema 1988). This suggests strongly that olfaction is used to localize bait, although the various proposed hypotheses need not be mutually exclusive.

The performance of a baited trap may be measured by its 'field of attraction' and 'effective area' (Miller 1975, Sainte-Mane 1991). The field of attraction is the 
domain of bottom from which at least some individuals of the target species move towards the trap in response to odor from the bait. The effective area is the area of bottom necessary to account for trap numerical yield: it is the quotient of catch (no. of ind.) over density (ind. per unit area of bottom) of the target species. Under the assumption of odor-mediated aggregation, advectivediffusive models have been developed to estimate the area of the field of attraction of scavengers to bait (Eggers et al. 1982, Bohé-Lafrique 1985, Desbruyères et al. 1985, Gros \& Santarelli 1986, Rowe et al. 1986). These models assume an elliptical or circular spread of odor around the bait. Other models introduce a temporal component that accounts for development of the plume and time required by a scavenger to travel to the bait (Sainte-Marie \& Hargrave 1987, Priede et al. 1990).

No study has yet formally analyzed the relations between scavenger aggregation around bait and current dynamics. Overall, few studies exist that provide temporal patterns of scavenger aggregation around bait with records of current that are both spatially and temporally relevant. The exceptions focus on rapidly moving species for which precise determination of direction and/or time of arrival of animals was impossible given the limited camera field of view and/ or the frequency of photographs (Lampitt et al. 1983, Wilson \& Smith 1984, Bohé-Lafrique 1985, Hargrave 1985). Currents could conceivably affect scavenger arrival rates in many ways. A sudden and marked change of current direction might result in animals losing the scent (Thurston 1979, Busdosh et al. 1982, Bohé-Lafrique 1985), thus arrivals at the bait would be momentarily interrupted. Conversely, a gradual and sustained change of current direction might enhance arrival rate as new bottoms are exploited by the odor plume. Scavenger arrival rate is likely to depend also on current speed. Under conditions of rapid vs very slow flow, chemical and rheotactic gradients are steeper so animals may be better able to localize bait (Kleerekopper et al. 1975).

Camivorous gastropods are interesting models for the study of scavenger behavior and orientation to bait, because they move slowly and are easily tracked in situ (Atema \& Burd 1975, Sainte-Marie 1991). The waved whelk Buccinum undatum Linnaeus is a common, commercially-exploited, subtidal gastropod in the northern North Atlantic (Golikov 1968, Jalbert et al. 1989, Gendron 1992). Whelks (from hereon, the term whelk designates only $B$. undatum) are facultative scavengers (Nielsen 1975) which are reportedly attracted to bait from distances that rarely exceed $30 \mathrm{~m}$ (Himmelman 1988, McQuinn et al. 1988). Natural predators of whelks include the crabs Hyas araneus (Linnaeus) and Cancer irroratus Say (Thomas \& Himmelman 1988).

Using time-lapse photography, SCUBA and current recordings, we studied the temporal and spatial dynamics of whelks aggregating around bait at 2 sites with contrasting current regimes. Our first objective was to test the hypothesis that whelks arrive at bait from a downstream direction, thus supporting the view that odor is the main sensory clue for aggregation. The second objective was to measure relations between whelk arrival rate and current speed, current directional stability, and the number of whelk predators at the bait. With respect to the latter objective, we hypothesized that whelk arrival rate should be (1) enhanced during periods of gradual and sustained changes of current direction, (2) depressed during periods of sudden and marked changes of current direction, (3) enhanced when current speed is high, and (4) depressed when the crabs Cancer irroratus and Hyas araneus are abundant at the bait. Our observations support these predictions and provide new information for the formulation and testing of more realistic models of scavenger attraction to bait.

\section{MATERIALS AND METHODS}

Study sites and experimental protocol. Experiments were performed at 2 soft-bottom sites in the Mingan Archipelago, northern Gulf of Saint Lawrence, Canada (Fig. 1). Sites were selected for their accessibility, topographical uniformity, different current regimes, and abundance of carnivorous invertebrates. The first site (IF) was located off lle du Fantôme at $10 \mathrm{~m}$ depth and the second (AN) was in Anse des Noyés at $11 \mathrm{~m}$ depth.

To record whelk activity in the vicinity of bait (nearfield experiments), we used an Edgerton-Benthos deep-sea standard camera (28 mm lens) and flash with

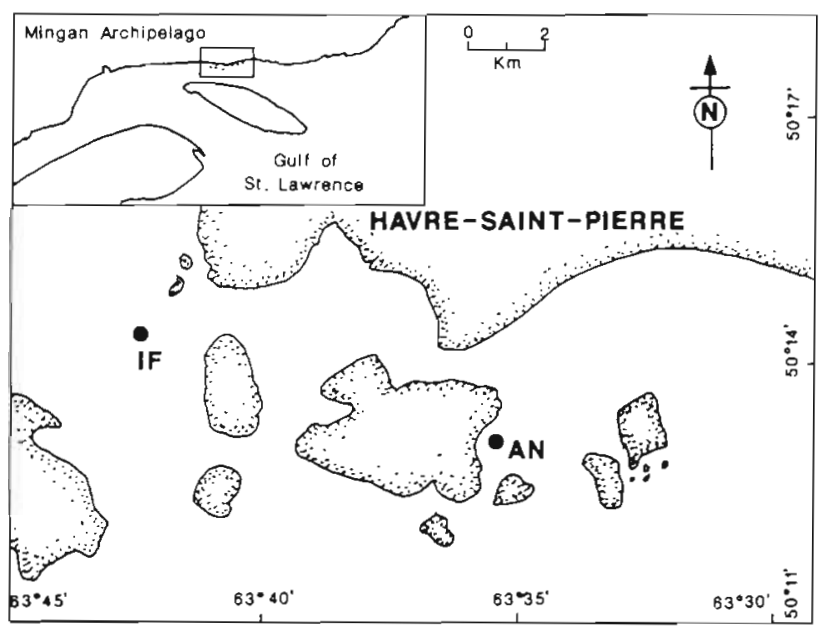

Fig. 1. Part of the Mingan Archipelago in the northern Gulf of Saint Lawrence (insert) and position of the experimental sites at lle du Fantôme (IF) and Anse des Noyés (AN) 
a black and white 125 ASA film. The camera was mounted on a stainless steel frame supported by 4 slender legs, with the lens $1.5 \mathrm{~m}$ above the bottom. A graduated ruler pointing north was fixed on the bottom within the $0.9 \times 1.5 \mathrm{~m}$ camera field of view. Bait consisted of $800 \mathrm{~g}$ of herring Clupea harengus Linnaeus that was fixed on the bottom at the center of the camera field. Half of the bait was shielded in a $1 \mathrm{~mm}$ Nitex bag and the other half was placed in a $2.5 \mathrm{~cm}$ mesh bag. Photographs were taken at 2 min intervals. Experiments lasted for $12 \mathrm{~h} 02 \mathrm{~min}$ at site IF, starting at 14:52 h on 20 July 1989, and for 25 h 12 min at site AN, starting at $14: 32 \mathrm{~h}$ on 17 August 1989. Concomitantly, water temperature and average speed and direction of current were recorded at 2 min intervals by Aanderaa RCM-7 (site IF) and InterOceans S4 (site AN) current meters located $5 \mathrm{~m}$ away from the bait and $1 \mathrm{~m}$ above bottom.

Photographs were projected on a $35 \times 35 \mathrm{~cm}$ digitizing table. Taxa were identified and enumerated. Whelks were classified according to 3 behavioral categories: arriving at bait, departing from bait, and wandering. Whelks in the last category entered or crossed the camera field but never moved towards the bait. The positions of the apex and of the anterior edge of each whelk shell were determined and the direction of the resulting vector gave the orientation of the whelk. The midpoint of the whelk vector and the center of bait were used to determine a whelk-to-bait vector, representing the distance and course to the bait. Shell height, measured from anterior edge to apex, and crawling speed were determined for whelks that were within $45 \mathrm{~cm}$ of the center of the camera field and that were not disturbed as they moved towards bait. The shell height of individual whelks was the mean of a least 2 measurements on different photographs. Stereoscopic photography is required to accurately measure objects if they are not flush with the bottom. However, the measurement error on shell height resulting from the use of single photographs taken in the same conditions (flat bottom, same camera elevation) is constant across sites, so data may be used for comparative purposes.

We used SCUBA diving to record whelk activity up to $25 \mathrm{~m}$ away from the bait (far-field experiments). A stake and a current meter separated by $30 \mathrm{~m}$ were installed at sites AN and IF. A slightly buoyant $25 \mathrm{~m}$ nylon rope graduated every $0.5 \mathrm{~m}$ was attached to the stake at $0.5 \mathrm{~m}$ from the ground. Control experiments with no bait at the stake and experiments in which the stake was baited with $800 \mathrm{~g}$ of herring were performed at site IF on 3, 11 (control only) and 14 August 1989, and at site AN on 16 and 18 (control only) August 1989. Divers performed circular surveys of the bottom around the stake with the graduated rope, a watch and a compass. For all whelks encountered, time of observation, behavior (buried, static or moving), orientation, and distance and direction to the stake were recorded. Static whelks were on the surface of sediments but divers could perceive no displacement. Moving whelks had fully deployed feet and displacement was obvious. Additionally, divers measured whelk crawling speeds at site IF on 23 August 1989 and at site AN on 24 August 1989 by placing a metre-ruler parallel to the course of whelks moving towards a bait and recording the time required to move $10 \mathrm{~cm}$.

The time that whelks spend feeding and the duration of the post-feeding phase were determined in the laboratory. Fourteen whelks, with shell heights of 76.6 to $96.2 \mathrm{~mm}$, were marked individually by painting a number on the shell. They were starved for $>14 \mathrm{~d}$ in a $0.6 \times 1.3 \mathrm{~m}$ tank with a sand bottom and flowing water at 2 to $4{ }^{\circ} \mathrm{C}$. Then, with a constant supply of fresh herring provided in the tank, whelk activity was monitored by video camera for $5 \mathrm{~d}$.

Treatment of data. In order to compare data from the different experiments, direction of current and whelkto-bait courses were standardized to $360^{\circ}$ and whelk orientation was corrected accordingly (e.g. standardized current direction: $245.5^{\circ}$ observed $+114.5^{\circ}=360^{\circ}$; corrected whelk orientation: $50^{\circ}$ observed $+114.5^{\circ}=$ $164.5^{\circ}$. Mean angle $(\theta)$ and the concentration parameter $r$ for corrected whelk orientations were calculated using statistics for circular distributions (Batschelet 1981). The Rayleigh test (Batschelet 1981) was used to verify the null hypothesis $\left(H_{0}\right)$ of random orientation of whelks, the alternative $\left(H_{1}\right)$ being that whelks oriented non-randomly. When $H_{1}$ was accepted, $95 \%$ confidence intervals $( \pm \delta)$ were used to test for agreement between mean whelk orientation and an hypothesized orientation (Batschelet 1981), i.e. $180^{\circ}$ for direct upstream movement and $360^{\circ}$ for direct movement towards bait.

In near-field experiments, the orientation of arriving, departing and wandering whelks was determined as the mean of orientations of a given whelk on all photographs where it appeared, excluding those where the whelk was at the bait or in the mass of aggregated feeders. The mean was thus generally based on 3 to 10 observations, depending on crawling speed and size of the feeding aggregation. Mean current direction and speed were calculated for the same time interval. Cumulative whelk arrivals and departures were plotted against elapsed time. The number of whelks at the bait was estimated as the difference between both curves at any given time, and the amount of time an individual spent at the bait was estimated as the difference between both curves for any given number of whelks.

Whelk arrival rate was defined as the number of whelks that arrived at bait in each photograph. We first 
used chronological clustering (Legendre et al. 1985) to determine if whelk arrival rate was constant or variable through time. Connectedness was fixed at $50 \%$ and different levels of statistical significance were used. Then, time series for whelk arrival rate, current speed and number of crabs at bait were smoothed (running mean on 5 consecutive observations) to eliminate high frequency variations and trends were extracted to make the series stationary (Legendre \& Legendre 1984). Each smoothed and detrended time series was autocorrelated and partial cross-correlations were used to determine if whelk arrival rate was related to current speed, current directional stability, and number of crabs at the bait. Current directional stability was the concentration parameter $r$ for 5 consecutive recordings of current direction immediately prior to whelk arrival at the bait. The concentration parameter may vary from 0 (very unstable) to 1 (very stable). We used time lags $\leq 6 \mathrm{~h}$ at site IF and $\leq 12 \mathrm{~h}$ at site AN for cross-correlation analyses. These time lags are ecologically meaningful since whelks take hours or days to reach bait from distances of 5 to $30 \mathrm{~m}$ (Himmelman 1988 and below). Correlations that are significant with short time lags presumably reflect interactions between the whelk and its environment in the vicinity of the bait; correlations with longer time lags should reflect interactions that occur further away from the bait.

In far-field experiments, we defined a priori 3 zones around the baited stake. Zone 1 was a $20^{\circ}$ sector downstream from the baited stake that was centered on current direction, Zone 2 was composed of two $20^{\circ}$ sectors that flanked each side of Zone 1, and Zone 3 was the remaining $300^{\circ}$ sector. The behavior and orientation of whelks in each of these zones were analyzed separately.

Mean values of shell height, crawling speed or time spent feeding are followed in text by 1 standard deviation. We used the $Z$-test to compare 2 means when data were normally distributed and homoscedastic (Scherrer 1984). When either of these conditions was not met by data, we used the Mann-Whitney $U$-test for 2-sample comparisons or the Kruskal-Wallis and a posteriori Dunn tests for multi-sample comparisons (Scherrer 1984). The G-test with William's correction (Sokal \& Rohlf 1981) was used to compare frequencies of behavior across zones or experiments. We used Fisher's exact test (SAS Institute Inc, 1989) in one case where $33 \%$ of cells in the contingency table had counts $<5$.

\section{RESULTS}

\section{Near-field experiments}

At site IF (Fig. 2), current direction was almost constant at $150^{\circ}$ from 0 to $3.5 \mathrm{~h}$ elapsed time and at $360^{\circ}$

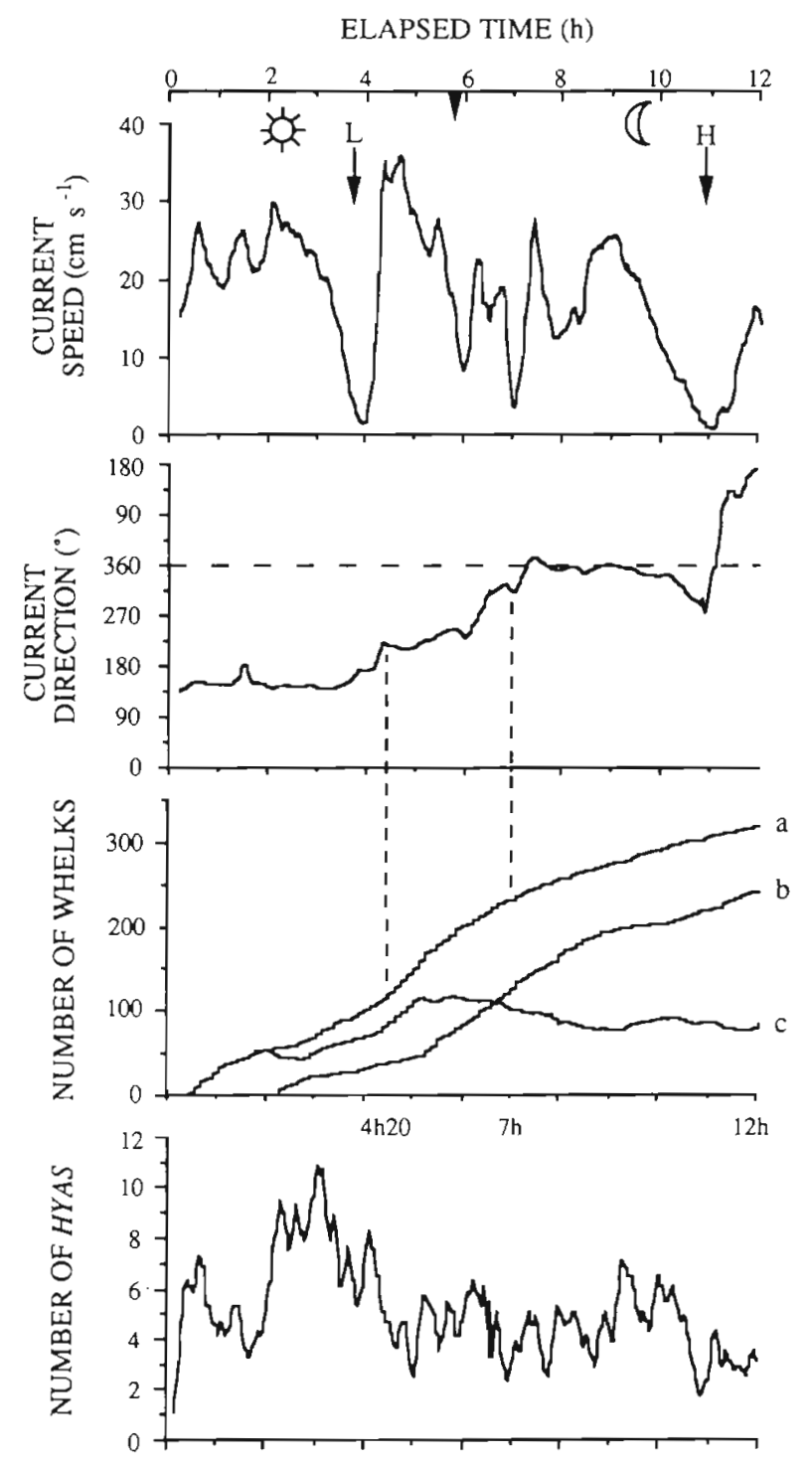

Fig. 2. Buccinum undatum. Current speed and direction, cumulative number of whelk arrivals (a) and departures (b) at bait, and instantaneous numbers of whelks (c) and Hyas araneus at bait, as a function of time elapsed since placement of bait at site IF (start: 14:52 h, 20 July 1989). Data plotted are running means on 5 consecutive observations at 2 min intervals. Arrowhead marks sunset and arrows mark low (L) and high $(H)$ tide. Vertical dashed lines identify sequences in arrival rate obtained by chronological clustering

from 7.5 to $10.5 \mathrm{~h}$ elapsed time. These 2 periods of directional stability preceded slack tides during which water was almost motionless. During the first $4 \mathrm{~h}$ of flood tide the current gradually turned from 150 to $360^{\circ}$, but in $20 \mathrm{~min}$ after high tide current direction shifted from 280 to $150^{\circ}$. The current only briefly flowed in the 10 to $135^{\circ}$ directions. Over the full tidal cycle, current speed varied from undetectable to $40 \mathrm{~cm} \mathrm{~s}^{-1}$ and the mean was $22 \mathrm{~cm} \mathrm{~s}^{-1}$.

At site AN (Fig. 3), the 2 recorded tidal cycles were 


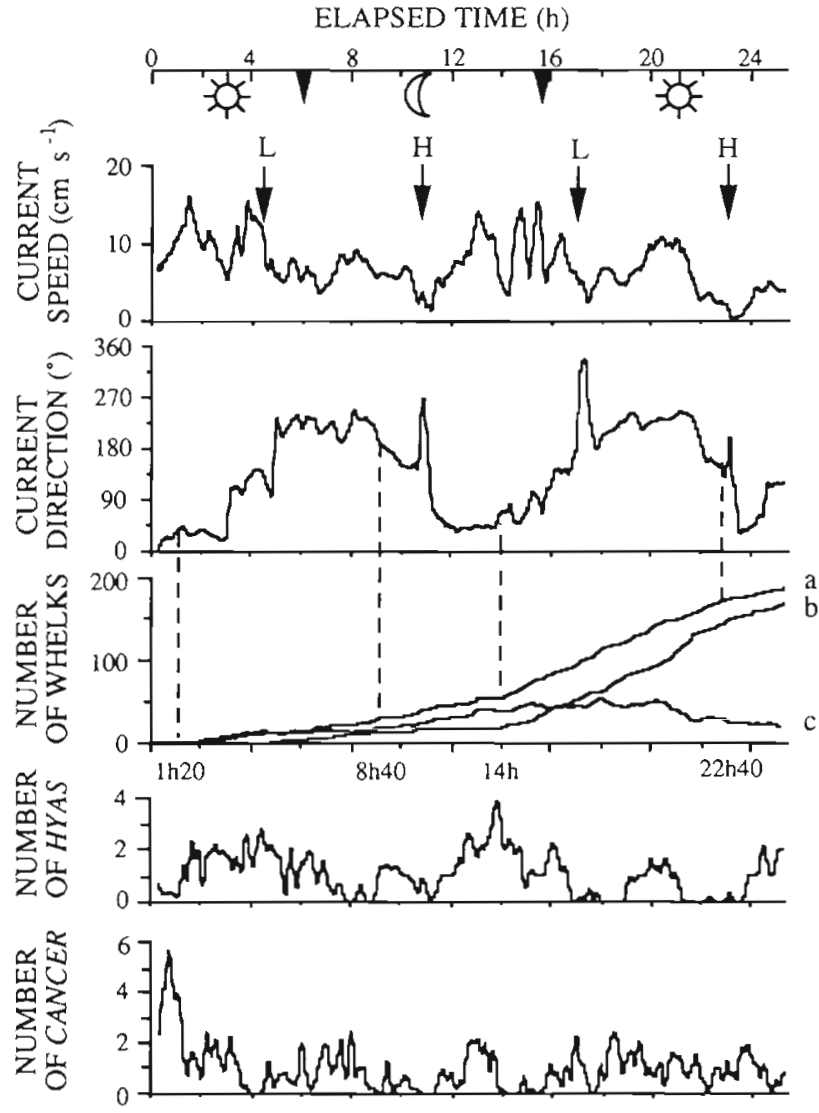

Fig. 3. Buccinum undatum. Current speed and direction, cumulative number of whelk arrivals (a) and departures (b) at bait, and instantaneous numbers of whelks (c), Hyas araneus and Cancer irroratus at bait, as a function of time elapsed since placement of bait at site AN (start: 14:32 h, 17 August 1989). Data plotted are running means on 5 consecutive observations at 2 min intervals. Arrowheads mark sunset or sunrise and arrows mark low (L) and high $(\mathrm{H})$ tide. Vertical dashed lines identify sequences in arrival rate obtained by chronological clustering

characterized by several sudden and marked changes in current direction. The general pattern of current direction was the following: while the tide ebbed the current turned for ca 5 h from ca 30 to $240^{\circ}$, and while the tide flooded the current oscillated around the $245^{\circ}$ direction $\left( \pm 20^{\circ}\right)$ for $\mathrm{ca} 4 \mathrm{~h}$ and then turned counterclockwise to a $150^{\circ}$ direction. Slack tides were periods of directional instability. Overall, the current only briefly flowed in the 265 to $15^{\circ}$ directions and current speed varied from undetectable to $16 \mathrm{~cm} \mathrm{~s}^{-1}$, with a mean of $7 \mathrm{~cm} \mathrm{~s}^{-1}$.

Lysianassoid amphipods were the most common animals observed near the bait, but they were too small to be accurately counted or identified from the photographs. Lysianassoids clearly arrived at bait from downstream directions. Brachyuran crabs were twice as abundant at site IF (mean $=5.2 \mathrm{crabs}$ photograph ${ }^{-1}$ ) as at site $\mathrm{AN}$ (mean $=2.2 \mathrm{crabs}$ photograph ${ }^{-1}$ ). Only Cancer irroratus and Hyas araneus were seen and the latter accounted for 51 and $96 \%$ of all brachyurans observed at sites $\mathrm{AN}$ and IF, respectively. A few anomuran crabs, Pagurus sp., were seen at both sites. Four asteroids, Leptasterias polaris (Müller \& Troschel), entered the camera field at site $\mathrm{AN}$ and 2 moved to the bait. Other animals appeared in the photographs but were never seen on the bait: 1 species of fish, probably Ammodytes sp., was seen on 71 occasions at site IF and on 56 occasions at site AN, the echinoid Strongylocentrotus droebachiensis (O. F. Müller) was seen 42 times at site $\mathrm{AN}$ and 17 times at site $\mathrm{IF}$, and the fish Myoxocephalus sp. was seen once at site AN.

At site IF, the first whelk arrived at the bait $10 \mathrm{~min}$ after the start of the experiment; over $12 \mathrm{~h} 02 \mathrm{~min}$, a total of 325 whelks arrived at the bait, 235 departed from the bait, and 43 wandered close to the bait. At AN, the first whelk arrived at the bait after $64 \mathrm{~min}$ and the total number of whelks observed for the first $12 \mathrm{~h}$ was much lower than at site IF: 48 arriving, 18 departing and 12 wandering. After 25 h 12 min, whelks arriving at site AN numbered 187, departing 169, and wandering 22. The relative number of whelks in the different categories of activity differed between sites IF and AN for the first $12 \mathrm{~h}$ of bait deployment $\left(G_{\mathrm{adj}}=10.62\right.$, $p<0.01$ ) and between the first and second $12 \mathrm{~h}$ periods at site AN $\left(G_{a d 1}=16.42, \mathrm{p}<0.001\right)$.

Arriving, departing or wandering whelks could be followed through several consecutive photographs (Fig. 4). Tracking became impossible once whelks joined the mass of aggregated feeders. Some whelks abruptly changed their trajectory in the presence of crabs. Others made wide loops from one point to another on the bait. It is possible that some whelks left the camera field and then re-entered.

At sites IF and AN, $100 \%$ and $90 \%$ of the whelks, respectively, arrived at the bait from a downstream direction (Fig. 5). The hypothesis of random orientation with respect to current direction was rejected $(p<0.001)$ but the $95 \%$ confidence interval for the mean orientation of whelks arriving at the bait did not include the a priori $180^{\circ}$ direction (Fig. 5). The shell height of whelks arriving at the bait did not differ $(Z=1.25, \mathrm{p}>0.05)$ between site IF $(74.5 \pm 10.3 \mathrm{~mm}, \mathrm{n}=158)$ and site $\mathrm{AN}$ $(72.0 \pm 10.0 \mathrm{~mm}, \mathrm{n}=31)$. However, the crawling speed was less $(Z=5.68, p<0.01)$ at site $\operatorname{IF}(7.3 \pm 2.6 \mathrm{~cm}$ $\left.\mathrm{min}^{-1}, \mathrm{n}=158\right)$ than at site AN $\left(11.4 \pm 3.8 \mathrm{~cm} \mathrm{~min}^{-1}, \mathrm{n}=\right.$ 31). Multiple regression of crawling speed on whelk shell height and current speed was not significant (site IF: $F=1.69, \mathrm{p}=0.19$; site AN: $F=2.00, \mathrm{p}=0.15$ ). Temperature during experiments varied from 3.4 to $7.6^{\circ} \mathrm{C}$ at site IF and from 6.8 to $7.8^{\circ} \mathrm{C}$ at site AN.

Whelks departing from the bait at both sites were oriented non-randomly with respect to current direc- 


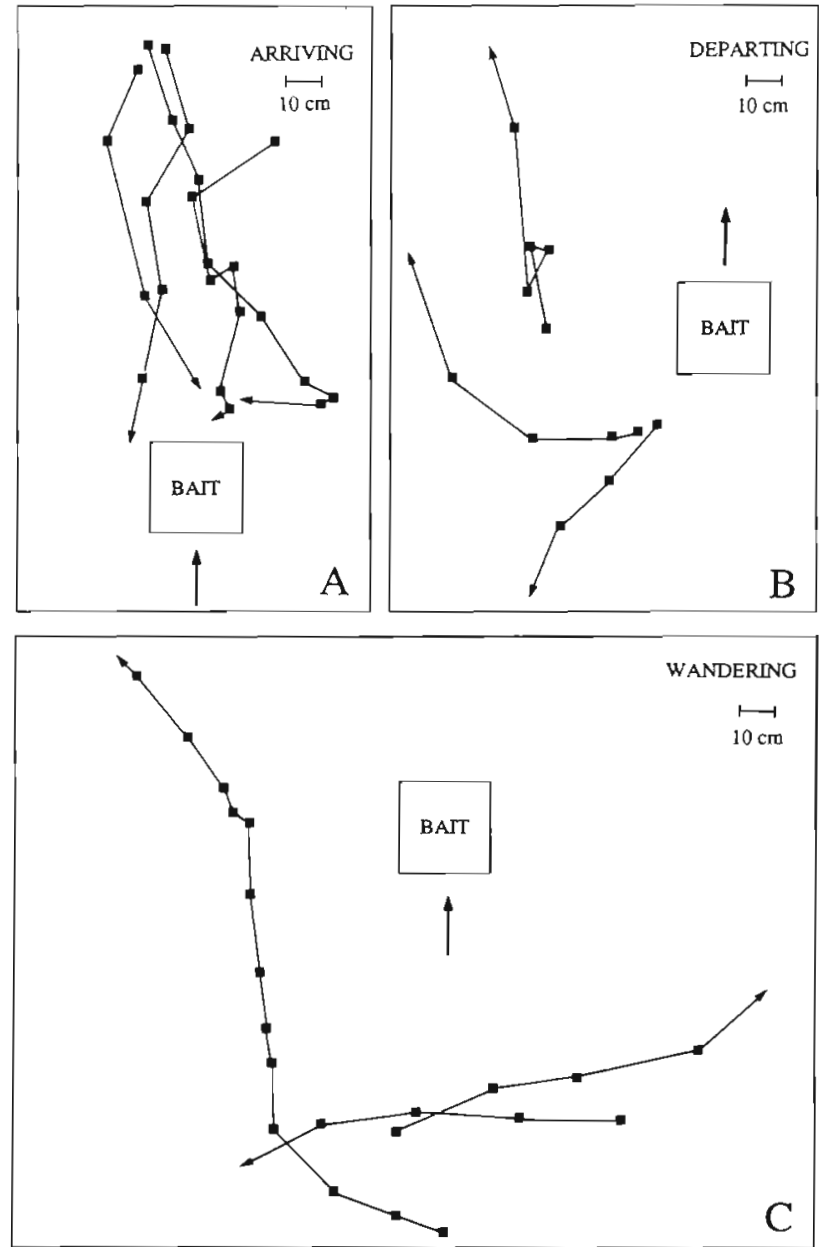

Fig. 4. Buccinum undatum. Example trajectories of arriving, departing and wandering whelks relative to current direction (arrow) and the location of the bait based on observations at 2 min intervals. Bait is not to scale

tion $(\mathrm{p}<0.001)$. They tended to move away perpendicularly $\left(278^{\circ}\right)$ to current at site AN or roughly in the same direction as current at site IF (Fig. 5), Wandering whelks showed no preferential orientation with respect to current direction (Fig. 5).

Whelks stayed at the bait for $170 \pm 45 \mathrm{~min}$ at site IF ( $\mathrm{n}=235$ ) and for $214 \pm 74$ min at site AN ( $\mathrm{n}=169)$. Whelks in the laboratory spent an average of $170 \pm 54$ $\min (n=14)$ at the bait before moving away. These 3 estimates were heterogeneous (data heteroscedastic: Kruskal-Wallis test, $H=40.57, \mathrm{p}<0.001$ ) due only to a difference between the 2 field estimates (Dunn's test, $\mathrm{p}<0.001)$. Whelks in the laboratory retumed to the bait $27.7 \pm 20.9 \mathrm{~h}$ (range: 2.9 to $74.9 \mathrm{~h}$ ) after their first meal was finished.

Chronological clustering detected 3 sequences $(\alpha=$ $0.025)$ in the time series for whelk arrival rate at site IF (Fig. 2). From 0 to 4 h 20 min elapsed time, the mean arrival rate was 23.8 whelks $\mathrm{h}^{-1}$ as current flowed
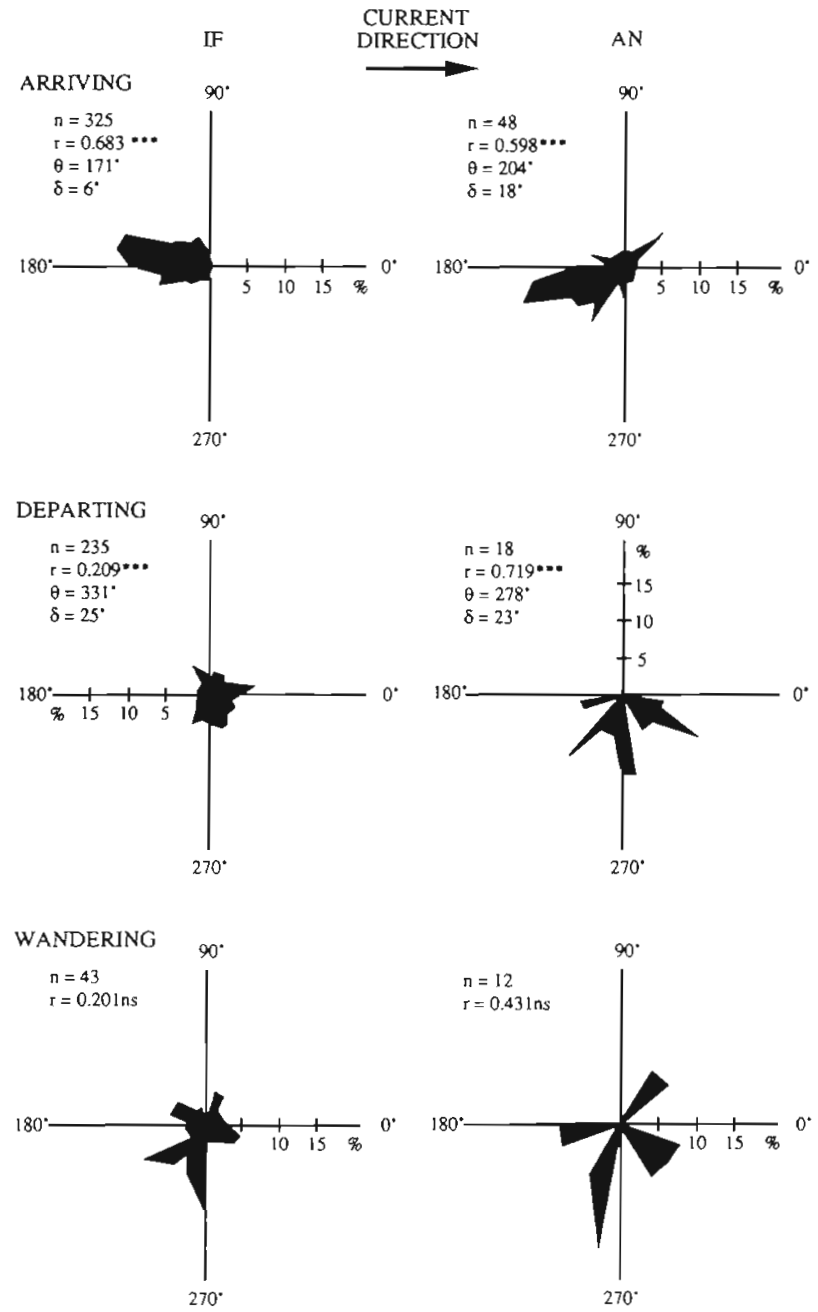

Fig. 5. Buccinum undatum. Orientation of whelks arriving at, departing from, and wandering by bait for a standard $360^{\circ}$ current direction at site IF on 20 July 1989 and at site AN on 17 August 1989. At site AN orientation of whelks was determined only for the first $12 \mathrm{~h}$ of bait exposure. Data are plotted for $5^{\circ}$ sectors as a percentage of total number of individuals ( $n$ ). The concentration parameter $r$ and where appropriate the mean $(\theta)$ and $95 \%$ confidence interval $(\delta)$ for whelk direction are given. The Rayleigh test was used to determine if whelks were randomly $\left(H_{0}\right)$ or non-randomly $\left(H_{1}\right)$ oriented. ns: not significant; $\cdots p<0.001$

almost constantly in the same direction. From 4 h 20 min to $7 \mathrm{~h}$ elapsed time, the mean arrival rate increased to 44.6 whelks $\mathrm{h}^{-1}$ as currents gradually rotated from 220 to $315^{\circ}$. Finally, from 7 h to 12 h 02 min elapsed time, the mean arrival rate decreased to 16.4 whelks $\mathrm{h}^{-1}$ and this coincided with a long period of directionally stable currents.

At site AN, 5 sequences were apparent $(\alpha=0.1)$ in the time series for whelk arrival rate (Fig. 3). From 0 to $1 \mathrm{~h} 20 \mathrm{~min}$ elapsed time, the mean arrival rate was 0.7 whelks h ${ }^{-1}$. From 1 h 20 min to 8 h 40 min elapsed time, the mean arrival rate was 3.6 whelks $\mathrm{h}^{-1}$ as current 
direction changed erratically from 30 to $240^{\circ}$, and from $8 \mathrm{~h} 40 \mathrm{~min}$ to $14 \mathrm{~h}$ it increased to 6.0 whelks h ${ }^{-1}$ while the current again rotated over the same sector. The highest mean arrival rate, 12.0 whelks $\mathrm{h}^{-1}$, was recorded from 14 to $22 \mathrm{~h} 40 \mathrm{~min}$ elapsed time as the current exploited the 30 to $240^{\circ}$ sector for the third time. Finally, from $22 \mathrm{~h} 40$ min to 25 h 12 min elapsed time, the mean arrival rate decreased to 6.3 whelks $\mathrm{h}^{-1}$ and this was coincident with the fourth exploitation by current of the 30 to $240^{\circ}$ sector.

Autocorrelations revealed no cyclicity in the temporal patterns of current speed, number of crabs or whelk arrival rate at the bait. However, current directional stability was autocorrelated for a $2 \mathrm{~h} 30 \mathrm{~min}$ lag at site IF $(\mathrm{r}=0.35, \mathrm{p}<0.05)$ and for a $6 \mathrm{~h} 06 \mathrm{~min}$ lag at site AN ( $r=0.36, p<0.05)$.

The correlograms of whelk arrival rate with current directional stability were marked by frequent negative and positive spikes, but there was no clear trend at either site (Figs. 6 \& 7). Correlations between whelk arrival rate and current speed followed the same pattern at sites AN and IF: they were positive with no or small time lags, but tended to be negative with long time lags (Figs. $6 \& 7$ ). At site AN, a cyclicity of approximately $2 \mathrm{~h}$ was apparent in the correlogram of whelk arrival rate with current speed (Fig. 7). Correlations

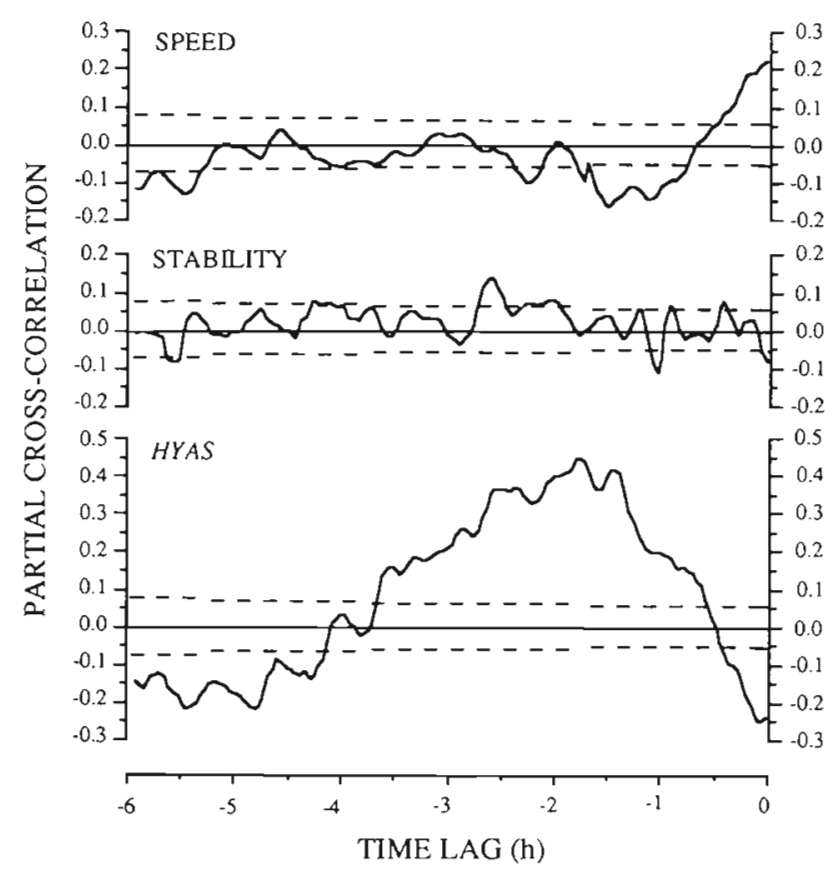

Fig. 6. Buccinum undatum. Correlograms for partial crosscorrelations of whelk arrival rate with current speed, current directional stability, and instantaneous number of Hyas araneus at bait at site IF on 20 July 1989. Dashed lines mark the $5 \%$ significance level between whelk arrival rate and numbers of Hyas araneus at the bait were negative with no or small time lags, positive with time lags of 1.5 to $6.5 \mathrm{~h}$ at site $\mathrm{AN}$ and of 0.5 to $3.5 \mathrm{~h}$ at site $\mathrm{IF}$, and then again negative for longer time lags (Figs. $6 \& 7$ ). At site AN, correlations between whelk arrival rate and numbers of Cancer irroratus at the bait were negative with time lags $<1 \mathrm{~h}$, but with longer time lags alternating positive and negative effects occurred.

\section{Far-field experiments}

There was no significant difference in the behavior of whelks between the different control experiments $\left(G_{\text {adj }}\right.$ $=5.43, p>0.75)$, so data were pooled in Table 1 . In the absence of bait, $68 \%$ of the whelks were static and oriented downstream at $360^{\circ}$, and $7.8 \%$ were buried. Only $24.2 \%$ of whelks were moving and they oriented randomly with respect to current direction.

With bait present, all whelks in the $20^{\circ}$ downstream sector (Zone 1) and $75.5 \%$ of those in the 2 flanking $20^{\circ}$ sectors (Zone 2) were moving (Table 2, Fig. 8). Moving whelks were oriented towards the bait, rather than directly against current (Table 2 ). In the remaining $300^{\circ}$ sector (Zone 3 ) only $39.1 \%$ of whelks were moving and

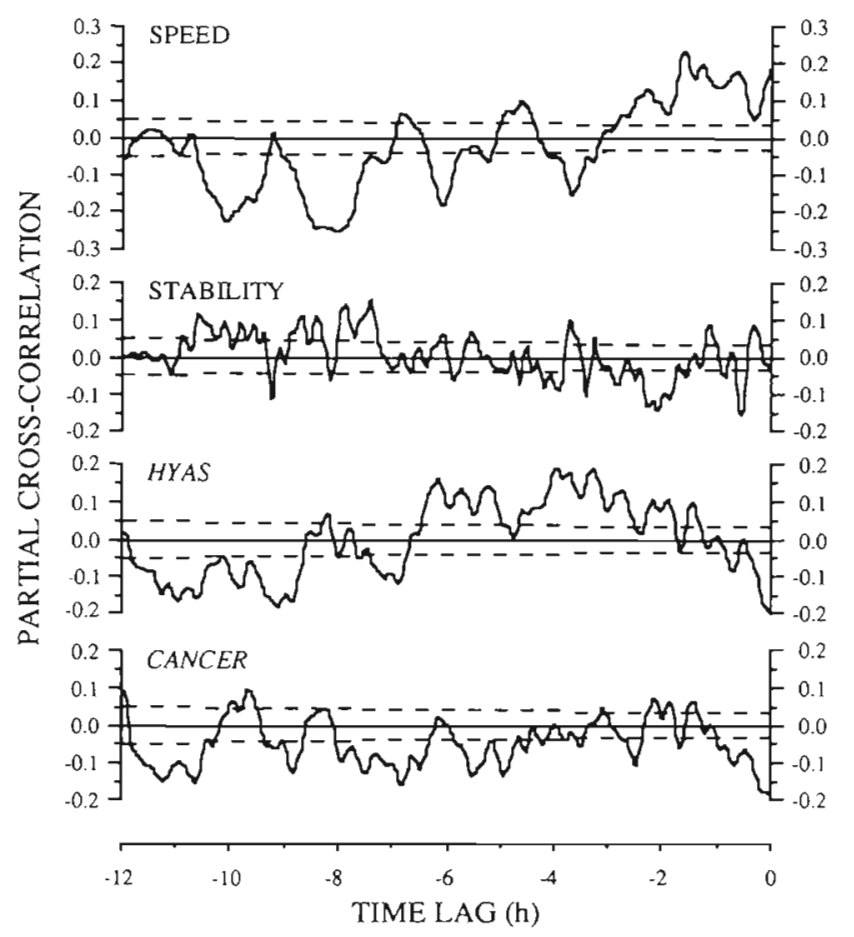

Fig. 7. Buccinum undatum. Correlograms for partial crosscorrelations of whelk arrival rate with current speed, current directional stability, and instantaneous numbers of Hyas araneus and Cancer irroratus at bait at site AN on 17 August 1989. Dashed lines mark the 5\% significance level 
they oriented randomly with respect to current direction and the position of the bait. Behavior of individuals differed across the 3 zones (Fisher's exact test, $p<0.001$ ), but individuals in Zone 3 did not behave differently from those in control experiments $\left(G_{\mathrm{ad}}\right)=$ $4.98, p>0.1)$. The diver-estimated crawling speed of whelks that moved towards bait was $9.2 \pm 1.7 \mathrm{~cm}$ $\min ^{-1}(\mathrm{n}=14)$ at site IF and $15.1 \pm 4.4 \mathrm{~cm} \mathrm{~min}^{-1}$ ( $\mathrm{n}=$ 10) at site $A N$, and the difference between sites was significant (data heteroscedastic: Mann-Whitney $U$ test, $U=125, \mathrm{p}<0.001$ ).

Moving whelks at site IF left distinct trails in the organic mat at the surface of sediments. Thus, hours after placing the bait at the stake, we could determine maximum distance of attraction to bait by backtracking trails away from the stake. Trails (1) started at pits created by the whelk as it unburied, (2) suddenly ended, indicating that the whelk was quiescent prior to moving towards the bait, or (3) were marked by an abrupt change in course, indicating that the whelk was headed in another direction before moving towards the bait. The maximum distance for attraction to bait was apparently $20 \mathrm{~m}$, during long periods of directionally stable currents exceeding $20 \mathrm{~cm} \mathrm{~s}^{-1}$.

\section{DISCUSSION}

\section{Orientation and distance of attraction to the bait}

Far-field experiments are more appropriate than near-field experiments for the testing of hypotheses on whelk orientation mechanisms for 2 reasons. First, the $10 \times 30 \mathrm{~cm}$ bait represented a diffuse target in the $1.4 \mathrm{~m}^{2}$ camera field of view, but a point target in the $1963.5 \mathrm{~m}^{2}$ diver survey area. Therefore, many different straight trajectories could lead a given whelk to the bait

Table 1. Buccinum undatum. Absolute (n) and relative frequencies (\% of total $\mathrm{n}$ ) for whelks in different categories of behavior, determined by SCUBA divers during control experiments. Data were pooled from surveys conducted on 3,11 and 14 August 1989 at site IF and on 16 and 18 August 1989 at site AN. All whelk orientations were corrected for a standard $360^{\circ}$ current direction. The concentration parameter $r$ and where appropriate the mean angle $\left(\theta\right.$, in $\left.{ }^{\circ}\right)$ for whelk orientation are given. The Rayleigh test was used to determine if whelks were randomly $\left(H_{0}\right)$ or non-randomly $\left(H_{1}\right)$ oriented. ns: not significant; $\cdots:$ p $<0.001$

\begin{tabular}{lrrrrc|}
\hline \multirow{2}{*}{ Behavior } & \multicolumn{2}{c}{ Frequency } & \multicolumn{2}{c|}{ Orientation } \\
& $\mathrm{n}$ & $\%$ & \multicolumn{2}{c}{$r$} & $\theta$ \\
\hline Moving & 31 & 24.2 & $0.26 \mathrm{~ns}$ & - \\
Static & 87 & 68.0 & 0.32 & $\cdots$ & 360 \\
Buried & 10 & 7.8 & - & - \\
\hline
\end{tabular}

when it was close by, but only 1 straight trajectory would be effective for a distant whelk. Second, agonistic interactions between whelks and other animals, which cause whelks to modify their direction of movement independently of current and feeding stimuli (herein), are more common near than far from the bait (Lapointe \& Sainte-Marie unpubl.). These reasons explain in part why whelks moving towards the bait were less uniformly oriented in near-field $(r=0.60$ to 0.68 ) than in far-field ( $r=0.84$ to 0.94 ) experiments.

In far-field experiments, whelks moved towards the bait only from a 20 to $60^{\circ}$ downstream sector (Fig. 8). This observation supports the hypothesis that odor is the main stimulus for aggregation around bait. Whelks outside the downstream sector were apparently unaware of the bait and most were quiescent (Table 2), just as whelks in control experiments (Table 1). Upstream movement to bait and lack of response by animals away from the presumed path of the odor plume were also observed for an amphipod (Busdosh et al. 1982) and a crustacean decapod (Jernakoff \& Phillips 1988).

The fact that whelks moved towards the bait and not against current per se (Table 2, Figs. 5 \& 8) indicates that the orientation mechanism depends to some extent

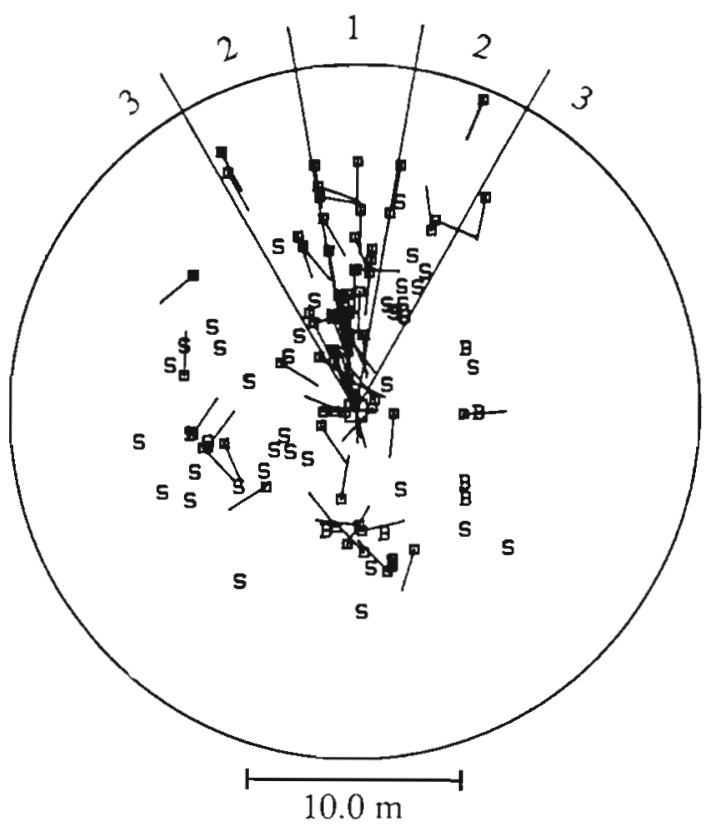

Fig. 8. Buccinum undatum. Behavior of whelks around bait. Data are from experiments conducted at site AN on 16 August 1989, and at site IF on 3 and 14 August 1989. Positions and orientations of whelks were corrected for a standard $360^{\circ}$ current direction. Zone 1 is a $20^{\circ}$ sector centered on current direction, downstream from the bait which is located at the center of the survey area. Zone 2 is composed of two $20^{\circ}$ sectors that flank each side of Zone 1 , and Zone 3 is the remaining $300^{\circ}$ sector. B: buried whelks; S: static whelks; moving whelks are marked by a square and a short line, the latter showing direction of movement 
Table 2. Buccinum undatum. Absolute ( $\mathrm{n}$ ) and relative frequencies ( $\%$ of total $\mathrm{n}$ ) for whelks in different categories of behavior in zones around a baited stake. Zone 1 is a $20^{\circ}$ sector immediately downstream from bait, Zone 2 comprises two $20^{\circ}$ sectors flanking Zone 1 on either side, and Zone 3 is the remaining $300^{\circ}$ sector. Data were pooled from experiments conducted on 3 and 14 August 1989 at Site IF and on 16 August 1989 at Site AN. Whelk orientations were corrected for a standard $360^{\circ}$ current direction or $360^{\circ}$ course to bait. The concentration parameter $r$ and where appropriate mean orientation $\left(\theta\right.$, in $\left.{ }^{\circ}\right)$ and $95 \%$ confidence interval $(\delta$, in ') for whelks are given. The Rayleigh test was used to determine if whelks were randomly $\left(H_{0}\right)$ or non-randomly $\left(H_{1}\right)$ oriented. The hypotheses $(H)$ of movement directed towards the bait $\left(360^{\circ}\right)$ or upstream $\left(180^{\circ}\right)$ are accepted if the confidence interval includes the postulated direction. ns: not significant; $\cdots . p<0.001$

\begin{tabular}{|c|c|c|c|c|c|c|c|}
\hline & \multirow{2}{*}{$\begin{array}{l}\text { Zone } 1 \\
\text { Moving }\end{array}$} & \multicolumn{3}{|c|}{ Zone 2} & \multicolumn{3}{|c|}{ Zone 3} \\
\hline & & Moving & Static & Buried & Moving & Static & Buried \\
\hline $\mathrm{n}$ & 38 & 37 & 11 & 1 & 25 & 33 & 6 \\
\hline$\%$ & 100.0 & 75.5 & 22.4 & 2.1 & 39.1 & 51.6 & 9.3 \\
\hline \multicolumn{8}{|c|}{$H=360^{\circ}$} \\
\hline$r$ & $0.94 \cdots$ & $0.89 \cdots$ & $0.17 \mathrm{~ns}$ & - & $0.35 \mathrm{~ns}$ & $0.15 \mathrm{~ns}$ & - \\
\hline$\theta$ & 353 & 354 & - & - & - & - & - \\
\hline$\delta$ & $\begin{array}{c}{ }^{7} \\
\text { H accepted }\end{array}$ & $\begin{array}{c}9 \\
\text { H accepted }\end{array}$ & - & - & - & - & - \\
\hline \multicolumn{8}{|c|}{$H=180^{\circ}$} \\
\hline$r$ & $0.94^{\cdots} \cdots$ & $0.84^{\cdots} \cdot$ & $0.18 \mathrm{~ns}$ & - & $0.08 \mathrm{~ns}$ & $0.22 \mathrm{~ns}$ & - \\
\hline$\theta$ & 169 & 165 & - & - & - & - & - \\
\hline$\delta$ & $\begin{array}{l}7 \\
\mathrm{H} \text { rejected }\end{array}$ & $\begin{array}{l}12 \\
\mathrm{H} \text { rejected }\end{array}$ & - & - & - & - & - \\
\hline
\end{tabular}

on chemotaxis, certainly not on rheotaxis alone. This is consistent with the observation that whelks orient to bait in still water (Brock 1933). Even though the organ for olfaction in whelks and other neogastropods, the osphradium, is unpaired and located in the mantle cavity (Bailey \& Laverack 1963), the side to side movement of the inhalant siphon offers the possibility of orientation by comparison of stimulus concentration (Kohn 1961).

The maximum distance for attraction of whelks to the bait in our experiments was apparently $20 \mathrm{~m}$. This occurred with fast and directionally stable currents, which are conducive to the development of a long and narrow odor plume (Sainte-Marie \& Hargrave 1987). McQuinn et al. (1988) reported that whelks were attracted to baited traps from substantially greater distances. In 7 out of 8 tag-recapture experiments whelks came from release points up to $30 \mathrm{~m}$ away from a baited trap, and in 1 experiment 2 whelks were recaptured from a distance of $50 \mathrm{~m}$. However, it is possible that movement towards the baited trap in the McQuinn et al. (1988) experiments was not initially induced by odor from the bait: active searching or anomalous movement due to experimental procedure are alternative possibilities (Sainte-Marie 1991).

The time whelks take to travel any given distance to a bait is generally much greater than would be expected assuming a constant crawling speed, continuous movement, and a straight trajectory. In theory, whelks crawling at measured speeds of 7 to $30 \mathrm{~cm}$ min $^{-1}$ would take only 67 to 286 min to reach a bait from a distance of $20 \mathrm{~m}$. However, Himmelman (1988) observed that the peak recapture rate of tagged whelks released downstream at 5,10 and $18 \mathrm{~m}$ from a baited trap was $6 \mathrm{~h}, 1 \mathrm{~d}$ and $2 \mathrm{~d}$, respectively. The crawling speed of gastropods may depend on temperature and substrate (Miller 1974, Nickell \& Moore in press); the values used above are extremes (herein; Pearce \& Thorson 1967, Gros \& Santarelli 1986, Himmelman 1988, Nickell \& Moore in press).

\section{Factors affecting arrival rate at the bait}

On the flat, uniform bottoms chosen for our experiments, currents and predators were the only factors that could have affected whelk movement towards the bait. One may demonstrate theoretically that current directional stability plays an important role for whelk attraction to bait. Assume that a fully-developed odor plume rotates clockwise around a bait (Fig. 9). Following Sainte-Marie \& Hargrave (1987), also assume that odor concentration (1) decreases along the plume's centerline with distance from the bait and (2) follows a normal distribution across the plume at any given distance from the bait. The plume's boundary is determined by a threshold concentration of odor below which whelks do not initiate movement towards the bait, and its shape and surface area do not change through time. Now consider a whelk ( $\left.W_{0}\right)$ located on 


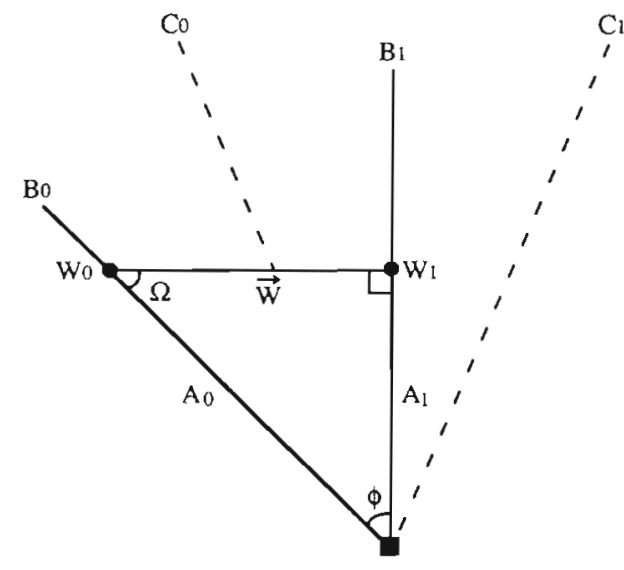

Fig. 9. Movement of a whelk at the periphery of an odor plume rotating clockwise around a bait. The plume's centerline $\left(C_{0}\right.$ and $C_{1}$ ) and left boundary $\left(B_{0}\right.$ and $\left.B_{1}\right)$ at 2 consecutive times are shown. $\phi$ : angle of rotation of the plume, $\vec{W}$ : shortest trajectory the whelk may take to reach $B_{1}$ from $B_{0}$ at an angle $\Omega$ with $B_{0}$ and at $90^{\circ}$ with $B_{1} ; A_{0}$ and $A_{1}$ : distances separating the whelk from the bait at positions $W_{0}$ and $W_{\mathrm{t}}$ respectively

the boundary $\left(B_{0}\right)$ to the left of the plume's centerline $\left(C_{0}\right)$, at a distance $A_{0}$ from the bait. If the plume rotates with an angle $\phi$, its new boundary and centerlíne are at $B_{1}$ and $C_{1}$, respectively. The shortest trajectory a whelk may take to move to the plume's new boundary is $\vec{W}$, which is at an angle $\Omega$ with $B_{0}$ and at $90^{\circ}$ with $B_{1}$. The distance to be travelled is

$$
|W|=A_{0} \sin \phi .
$$

Using this equation we calculated the critical distances from the bait at which tracking of an odor plume is impossible for a whelk, for various rates of plume rotation and 2 extreme crawling speeds (Fig. 10). However, because animals that rely on chemotaxis to localize bait tend to orient upstream towards the plume's centerline (McLeese 1973), the critical distances may be overestimated. Finally, the model clearly implies that whelks will spiral to bait if currents rotate.

Partial cross-correlations between whelk arrival rate and current directional stability were inconsistent across sites (Figs. $6 \& 7$ ). We realized a posteriori that current directional stability, measured as $r$ over $10 \mathrm{~min}$, confounded 2 sources of variation having different implications for whelk attraction to the bait. The first is a gradual change of current direction, for which we predict an enhanced arrival rate because current rotation is not sufficient to cause whelks to lose the odor plume and new grounds are continuously exploited by the odor plume. The second is a current oscillation around a mean direction. This will cause the arrival rate to decrease as the population downstream from the bait is gradually depleted, because whelks tend to be quiescent in the absence of feeding stimuli (Table 1)

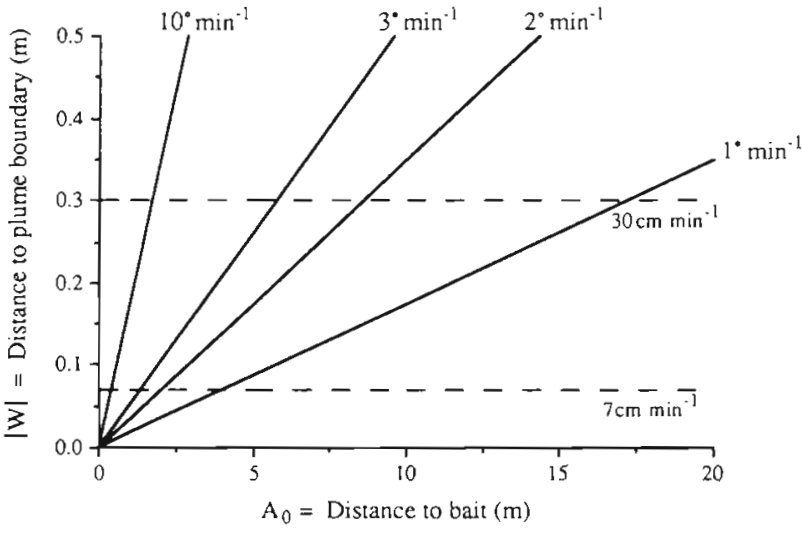

Fig. 10. Buccinum undatum. Critical distances $\left(A_{0}\right)$ from bait at which tracking of an odor plume is theoretically impossible for a whelk at the plume's boundary, given 2 extreme crawling speeds (dashed horizontal lines) and various rates of plume rotation (oblique solid lines). For example, a whelk moving at $7 \mathrm{~cm} \mathrm{~min}{ }^{-1}$ that is located further than $3.8 \mathrm{~m}$ from the bait is unable to track an odor plume rotating at $1^{\circ} \mathrm{min}^{-1}$. Refer to Fig. 9 and text for explanations on how the distance to plume boundary $(|W|)$ was calculated

(Himmelman 1988, Sainte-Marie 1991). Evidence for both effects exists at site IF (Fig. 2): from 4 h 20 min to $7 \mathrm{~h}$ elapsed time the arrival rate was 44.6 whelks $\mathrm{h}^{-1}$ as current rotated clockwise at an average rate of $0.6^{\circ}$ $\min ^{-1}$, compared to only 23.8 whelks $\mathrm{h}^{-1}$ from 0 to $4 \mathrm{~h}$ 20 min elapsed time (in spite of a high arrival rate when the whelk population was initially sollicited by the bait) and 16.4 whelks $\mathrm{h}^{-1}$ from $7 \mathrm{~h}$ to $12 \mathrm{~h} 02$ elapsed time when current direction was mostly constant.

Extreme current directional instability may have been a major factor causing the long delay before first arrival and the subsequent low arrival rate of whelks at site AN. Within a single tidal cycle, 100 to $200^{\circ}$ shifts in current direction over 20 min were observed several times at site AN, compared to only once at site IF (Figs. $2 \& 3$ ). Such sudden changes of current direction would cause most whelks to lose the bait scent (Fig. 10), even though the odor plume has a 20 to $60^{\circ}$ spread. That whelks at site AN were interrupted in their movement to the bait is suggested by 3 consecutive increases of the mean arrival rate that were coincident with repeated exploitations of the same grounds (Fig. 3). For sake of simplicity, assuming that the field of attraction at site AN was circular, one may postulate that whelks originating from 3 concentric rings of bottom advanced to the bait successively during the 3 sequential periods of exploitation. During the first, a small number of individuals reached the bait from the smallest inner area; during the second and third, more individuals reached the bait from the increasing larger peripheral areas. This interpretation is consistent with the hypothesis that crawling speed is the main factor limiting effective area of whelk traps (Gros \& Santarelli 1986, Miller 1990). 
Considering the above, we infer that few, if any, whelks were attracted to the bait from the 40 to $105^{\circ}$ and 295 to $345^{\circ}$ directions at sites IF and AN, respectively. Indeed, the current flowed only briefly in the 10 to $135^{\circ}$ directions at site IF and in the 265 to $15^{\circ}$ directions at site $\mathrm{AN}$, and the odor plume had a maximum spread of $\pm 30^{\circ}$. Thus, the field of attraction at our experimental sites was not elliptical or circular, contrary to the assumption in several models to estimate scavenger abundance (e.g. Gros \& Santarelli 1986). Our findings support earlier conclusions that currents determine the field of attraction and effective area of a baited trap or hook (Olsen \& Laevastu 1983, Himmelman 1988, McQuinn et al. 1988).

At both sites we found a strong positive correlation between the arrival rate of whelks and current speed for small time lags (Figs. $6 \& 7$ ), which implies that whelks close to the bait benefited from faster currents. Models and experimental evidence show that faster currents decrease the spread of a plume at any given distance from the source (Lam et al. 1984, Sainte-Marie \& Hargrave 1987). Odor gradients across the plume will thus be steeper, so animals may orient more efficiently and move more directly to bait (Kleerekopper et al. 1975). Nickell \& Moore (1991, in press) also reported that fast currents may improve performance of whelks. Arrival rate will be enhanced only if whelk speed of movement is independent of current speed, as is the case for whelks in currents $<40 \mathrm{~cm} \mathrm{~s}^{-1}$ (herein; P. Béland, Institut national d'écotoxicologie, Montréal, unpubl. dataj. By contrast, fast currents may reduce the rate of movement of many natant scavengers (Shorey 1976, Lampitt et al. 1983, Sainte-Marie \& Hargrave 1987, Løkkeborg et al. 1989). For longer time lags, whelk arrival rate at both sites tended to be negatively correlated with current speed (Figs. $6 \& 7$ ). The reasons for this are unclear.

Correlations between whelk arrival rate and the numbers of Cancer irroratus at site AN and of Hyas araneus at sites IF and AN were negative with small time lags (Figs. 6 \& 7). Causality is a problem here, as whelks may be reacting to crabs or vice versa. However, the former interpretation is more likely because both crab species are natural predators of Buccinum undatum (Thomas \& Himmelman 1988) and are known to prevent or delay entry of whelks into baited traps (Hancock 1974, Miller 1990). Whelks avoided crabs on many occasions at sites AN and IF. In contrast to these negative effects, arrival rate of whelks and numbers of $H$. araneus at bait were positively correlated at sites AN and IF with a time lag of one to several hours. As they tear and feed at bait crabs may increase the quantity of attractants that are advected, thereby contributing to heightened response of distant whelks.

Our analyses and interpretation of whelk arrival rate depend on the assumption that all whelks that came to the bait were new arrivals, i.e. that no individual moved away from the bait and then returned to feed again. This was supported by laboratory observations showing a mean fasting period of $27 \mathrm{~h} 42$ min after the first meal was finished. Long post-feeding phases are characteristic of other neogastropods as well: $>2$ d for 3 Nassarius species (Crisp 1969) and ca $10 \mathrm{~d}$ for Bullia digitalis (Stenton-Dozey \& Brown 1988). Moreover, during dives we saw no peripheral concentrations of whelks around the bait, i.e. 'roosting' animals in Smith (1985), and departing whelks were observed to move steadily away from the bait. Finally, total arrivals (325 at site IF, 187 at site AN) were consistent with catch rates of 200 to 400 whelks trap ${ }^{-1} 24 \mathrm{~h}^{-1}$ in the Mingan Archipelago (Himmelman 1988, Sainte-Marie unpubl.).

We have demonstrated that whelk arrival rate at bait is affected by changes in the direction and speed of current, and in the number of predators at bait. It is clear that movement of whelks to bait rarely occurs in a continuous manner and along a straight trajectory. If this is true of other scavengers as well, models that use the time of first arrival at bait to measure scavenger density (Sainte-Marie \& Hargrave 1987, Priede et al. 1990) may generally produce underestimates.

Acknowledgements. V Lapointe was supported by scholarships from the Natural Sciences and Engineering Research Council of Canada and Québec Ministry of Education. We thank J.-L. Beaulieu, C. Cyr, D. Guay and F. Hazel for help in the field and laboratory, and P. Dutilleul, P. Gagnon, F.-J. Lapointe and P. Vinet for advice on statistical analyses. Suggestions by B. T. Hargrave, R. S. Kaufmann, A. Mauviel and 2 anonymous reviewers improved the manuscript.

\section{LITERATURE CITED}

Arnaud, P. M. (1970). Frequency and ecological significance of necrophagy among benthic species of the Antarctic coastal waters. In: Holdgate, M.W. (ed.) Antarctic ecology, Vol. 1. Academic Press, New York, p. 259-267

Atema, J. (1988). Distribution of chemical stimuli. In: Atema, J., Popper, A. N., Fay, R. R., Tavolga, W N. (eds.) Sensory biology of aquatic animals. Springer-Verlag, New York, p. $29-56$

Atema, J., Burd, G. D. (1975). A field study of chemotactic responses of the mud snail, Nassarius obsoletus. J. chem. Ecol. 1: 243-251

Bailey, D. F., Laverack, M. S. (1963). Central nervous responses to chemical stimulation of a gastropod osphradium. Nature, Lond. 200: 1122-1123

Batschelet, E. (1981). Circular statistics in biology. Academic Press, New York

Bohé-Lafrique, S. (1985). Les équarisseurs épibenthiques dans l'Atlantique nord-est profond. Doctoral thesis, Univ. AixMarseille II, Aix-Marseille

Brock, F. (1933). Analyse des Beute- und Verdauungsfeldes der Wellhornschnecke Buccinum undatum L. Zool. Anz. 6 : 243-250 
Busdosh, M., Robilliard, G. A., Tarbox, K., Beehler, C. L. (1982). Chemoreception in an arctic amphipod crustacean: a field study. J. exp. mar. Biol. Ecol. 62: 261-269

Crisp, M. (1978). Effects of feeding on the behaviour of Nassarius species (Gastropoda: Prosobranchia). J. mar. biol. Ass. U.K. 58: 659-669

Dahl, E. (1979). Deep-sea carrion feeding amphipods: evolutionary patterns in niche adaptation. Oikos 33: $167-175$

Dayton, P. K., Hessler, R. R. (1972) Role of biological disturbance in maintaining diversity in the deep sea. Deep Sea Res. 19: 199-208

Desbruyères, D., Geistdoerfer, P., Ingram, C. L., Khripounoff, A., Lagardère, J.-P. (1985). Répartition des populations de l'épibenthos carnivore. In: Laubier, L., Monniot, C. (eds.) Peuplements profonds du golfe de Gascogne. IFREMER, Brest, p. 233-252

Eggers, D. M., Rickard, N. A., Chapman, D. G., Whitney, R. R. (1982). A methodology for estimating area fished for baited hooks and traps along a ground line. Can. J. Fish. Aquat. Sci. 39: $448-453$

Gendron, L. 1992. Determination of the size at sexual maturity of the waved whelk Buccinum undatum Linnaeus, 1758, in the Gulf of St. Lawrence, as a basis for the establishment of a minimum catchable size. J. Shellfish Res. 11:1-7

Golikov, A. N. (1968). Distribution and variability of long-lived benthic animals as indicators of currents and hydrological conditions. Sarsia 34: 199-208

Gros, P., Santarelli, L. (1986). Méthode d'estimation de la surface de pèche d'un casier à l'aide d'une filière expérimentale. Oceanologica Acta 9: 81-87

Hancock, D. A. (1974). Attraction and avoidance in marine invertebrates - their possible role in developing artificial bait. J. Cons. Int. Explor. Mer 35: 328-331

Hargrave, B. T (1985). Feeding rates of abyssal scavenging amphipods (Eurythenes gryllus) determined in situ using time-lapse photography. Deep Sea Res. 32: 443-450

Himmelman, J. H. (1988). Movement of whelks (Buccinum undatum) towards a baited trap. Mar. Biol. 97: 521-531

Ingram, C. L., Hessler, R. R. (1983). Distribution and behavior of scavenging amphipods from the central North Pacific. Deep Sea Res. 30: 683-706

Isaacs, J. D., Schwartzlose, R. A. (1975). Active animals of the deep-sea floor Scient. A.m. 233: 85-91

Jalbert, P., Himmelman, J. H., Béland, P., Thomas, B. (1989). Whelks (Buccinum undatum) and other subtidal invertebrate predators in the northern Gulf of St. Lawrence Naturaliste can. 116: 1-15

Jernakoff, P., Phillips, B. F. (1988). Effect of a baited trap on the foraging movements of juvenile western rock lobsters Panulirus cygnus George. Aust. J. Mar. freshwat. Res. 39 $185-192$

Kohn, A. J. (1961). Chemoreception in gastropod molluscs Am. Zool. 1: 291-308

Kleerekopper, H., Gruber, D., Matis, J. (1975). Accuracy of localization of a chemical stimulus in flowing and stagnant water by the nurse shark, Ginglymostoma cirratum. J. comp. Physiol. 98: 257-275

Lam, D. C. L., Murthy, C. R., Simpson, R. B. (1984). Effluent transport and diffusion models for the coastal zone Springer-Verlag, New York

Lampitt, R. S., Merrett, N. R., Thurston, M. H. (1983). Interrelations of necrophagous amphipods, a fish predator and tidal currents in the deep sea. Mar. Biol. 74: 73-78

Legendre, L., Legendre, P. (1984). Ecologie numérique, Vol. 2 Le traitement multiple des données écologiques, 2nd ed. Masson, Paris
Legendre, P., Dallot, S., Legendre, L. (1985). Succession of species within a community: chronological clustering, with applications to marine and freshwater zooplankton. Am. Nat. 125: 257-288

Løkkeborg, S., Bjordal, A., Fernö, A. (1989). Responses of cod (Gadus morhua) and haddock (Melanogrammus aeglefinus) to baited hooks in the natural environment. Can. J. Fish. Aquat. Sci. 46: 1478-14.83

McLeese, D. W. (1973). Orientation of lobsters (Homarus americanus) to odor. J. Fish. Res. Bd Can. 30: 838-840

McQuinn, I. H., Gendron, L., Himmelman, J. H. (1988). Area of attraction and effective area fished by a whelk (Buccinum undatum) trap under variable conditions. Can. J Fish. Aquat. Sci. 45: 2054-2060

Miller, R. J. (1975). Density of the commercial spider crab Chionoecetes opilio, and calibration of the effective area fished per trap using bottom photography. J. Fish. Res. Bd Can. 32: 761-768

Miller, R. J. (1980). Design criteria for crab traps. J. Cons. Int Explor. Mer 39: 140-147

Miller, R. J. (1990). Effectiveness of crab and lobster traps Can. J. Fish. Aquat. Sci. 47: 1228-1251

Miller, S. L. (1974). Adaptive design of locomotion and foot form in prosobranch gastropods. J. exp. mar. Biol. Ecol. 14:99-156

Nickell, T. D., Moore, P. G. (1991). The behavioural ecology of epibenthic scavenging invertebrates in the Clyde Sea area: field sampling using baited traps. Cah. biol mar. 32 $353-370$

Nickell, T. D., Moore, P. G. (in press). The behavioural ecology of epibenthic scavenging invertebrates in the Clyde Sea area: laboratory experiments on attractions to bait in mov. ing water, underwater TV observations in situ and general conclusions. J. exp mar. Biol. Ecol.

Nielsen, C. (1975). Observations on Buccinum undatum L. attacking bivalves and on prey responses, with a short review on attack methods of other prosobranchs. Ophelia 13: $87-108$

Olsen, S., Laevastu, T. (1983). Fish attraction to baits and effects of currents on the distribution of smell from baits. NOAA Natn. Mar. Fish. Serv., NWAFC Processed Rep. 83-05

Okubo, A. (1980). Diffusion and ecological problems: mathematical models. Springer-Verlag, New York

Pearce, J. B., Thorson, G. (1967). The feeding and reproductive biology of the red whelk, Neptunea antiqua (L.). (Gastropoda, Prosobranchia). Ophelia 4: 277-314

Priede, J. G., Bagley, P. M., Armstrong, J. D., Smith, K. L., Jr., Merrett, N. R. (1991). Direct measurement of active dispersal of food-falls by deep-sea demersal fishes. Nature, Lond. 351. $647-649$

Priede, I. G., Smith, K. L., Jr., Armstrong, J. D. (1990). Foraging behavior of abyssal grenadier fish. inferences from acoustic tagging and tracking in the North Pacific Ocean. Deep Sea Res. 37: 81-101

Rowe, G. T., Sibuet, M., Vangriesheim, A. (1986). Domains of occupation of abyssal scavengers inferred from baited cameras and traps on the Demerara Abyssal Plain. Deep Sea Res. 33: 501-522

Sainte-Marie, B. (1991). Whelk (Buccinum undatum) movement and its implications for the use of tag-recapture methods for the determination of baited trap fishing parameters. Can. J. Fish. Aquat. Sci. 48: 751-756

Sainte-Marie, B., Hargrave, B. T (1987). Estimation of scavenger abundance and distance of attraction to bait. Mar. Biol. 94: 431-443

SAS Institute Inc. (1989). SAS/STAT User's Guide, Version 6. Fourth edn., Vol. 1 SAS Institute Inc., Cary, NC

Scherrer, B. (1984). Biostatistique. Gaëtan Morin, Chicoutimi 
Shorey, H. H. (1976). Animal communication by pheromones. Academic Press, New York

Smith, C. R. (1985). Food for the deep sea: utilization, dispersal, and flux of nekton falls at the Santa Catalina Basin floor. Deep Sea Res. 32: 417-442

Smith, C. R. (1986). Nekton falls, low-intensity disturbance and community structure of infaunal benthos in the deep sea. J. mar Res. 44: 417-442

Smith, K. L., Jr., Baldwin, R. J. (1982). Scavenging deep-sea amphipods: effects of food odor on oxygen consumption and a proposed metabolic strategy. Mar. Biol. 68: 287-298

Smith, K. L., Jr., Baldwin, R. J. (1984). Vertical distribution of the necrophagous amphipod Eurythenes gryllus in the North Pacific: spatial and temporal variation. Deep Sea Res. 31: 1179-1196

Sokal, R. R., Rohlf, F. J. (1981). Biometry, 2nd edn. W H. Freeman, New York

This article was submitted to the editor
Stenton-Dozey, J. M. E., Brown, A. C. (1988). Feeding, assimilation, and scope for growth in the scavenging sandybeach neogastropod Bullia digitalis (Dillwyn). J. exp. mar. Biol. Ecol. 119: 253-268

Stockton, W. L., DeLaca, T E. (1982). Food falls in the deep sea: occurrence, quality, and significance. Deep Sea Res 29: $157-169$

Thomas, M. L. H., Himmelman, J. H. (1988). Influence of predation on shell morphology of Buccinum undatum L. on Atlantic coast of Canada. J. exp. mar. Biol. Ecol. 115 $221-236$

Thurston, M. H. (1979). Scavenging abyssal amphipods from the north-east Atlantic Ocean. Mar. Biol. 51-55-68

Wilson, R. R. Jr., Smith, K. L. Jr. (1984). Effects on near-bottom currents on detection of bait by the abyssal grenadier fishes Coryphaenoides spp., recorded in situ with a video camera on a free vehicle. Mar. Biol. 84: 83-91

Manuscript first received: February 11, 1992

Revised version accepted: July 13, 1992 